\title{
The role of nursing in pediatric palliative home care - Experiences from Lower Saxony, Germany
}

\author{
Kerstin Kremeike, Dirk Reinhardt, Annette Sander \\ Pediatric Hematology and Oncology, Medical School Hannover, Hannover, Germany. \\ Correspondence: Kerstin Kremeike. Address: Carl-Neuberg-Strasse 1, 30625 Hannover, Germany. Email: \\ kremeike.kerstin@mh-hannover.de
}

Received: July 1, 2013

DOI : $10.5430 /$ jnep.v4n2p243

\author{
Accepted: November 25, 2013 Online Published: January 3, 2014 \\ URL: http://dx.doi.org/10.5430/jnep.v4n2p243
}

\begin{abstract}
Background: In 2007, the patient's right to specialized pediatric palliative home care (SPPHC) became law in Germany. In Lower Saxony, a German federal state with a low population density, an adequate care for children suffering from life-limiting conditions (LLC) should be ensured in the context of low patient numbers and low numbers of specialists. A close cooperation with regional primary health care providers can facilitate the performance of this task. Nursing home services play a decisive role in delivering pediatric palliative home care.
\end{abstract}

Methods: The descriptive retrospective study aimed on the evaluation of nursing home services involvement in and contribution to palliative care in children and adolescents. A second aim was to implement a SPPHC to assure an optimal care provision. Therefore, a standardized questionnaire survey was disseminated to 22 home nursing services, 14 (63\%) of them returned the completed form. Data analysis was descriptive. The evaluated needs have been included in the conception of a comprehensive SPPHC in Lower Saxony which was implemented in 2010.

Results: In 2008, the home nursing services reported on 168 patients suffering from life-limiting conditions. As incentives for delivering palliative home care, the nursing teams emphasized the support by a specialized team, a 24-hour on-call duty and the increase of educational programs. To meet this demand, a SPPHC was implemented. Since April 2010, a central office undertakes the coordination and administration, while different regional teams comprising nursing, medical and psycho-social specialists care for the children and adolescents suffering from complex conditions due to LLC. Additionally a central hotline service provides 24/7 specialist availability. During the first three years of operation, the SPPHC providers were involved in the management of 131 children suffering from LLC. In total, 6452 hours of SPPHC were delivered, predominantly spent on joint patient care with regional health care providers like nursing teams or resident physicians (30.2\%), driving time (22.5\%) and coordination of care (15.3\%). Nurses specialized in pediatric palliative care delivered $45.3 \%$ of SPPHC in Lower Saxony.

Conclusions: The provision of a comprehensive SPPHC in a region of low population density is possible. A high percentage of coordinative and logistic efforts is needed to enable the specialist care in each child and all areas. General nursing services and nurses specialized in pediatric palliative care as part of the SPPHC play a crucial role in delivering palliative home care for children and adolescents with LLC.

\section{Key words}

Children, Palliative care, Home care, Rural, Specialist nursing 


\section{Introduction}

A core standard in pediatric palliative care is the provision of care at the patients and families preferred place of care ${ }^{[1]}$. Bluebond-Langer et al. recently analyzed data regarding preferences for care and death in the pediatric palliative care setting ${ }^{[2]}$. Most of the analyzed retrospective studies found that the majority with up to $88 \%$ of children with cancer would have preferred home care according to their parents ${ }^{[3]}$. Only few data are available regarding children with other lifelimiting-conditions. However, provision of comprehensive pediatric palliative home care is still not reality in Europe. Availability of service often depends on geographic (urban vs. rural area) and infrastructural factors. Well developed services are particularly available to children with cancer, but patients in need of pediatric palliative care suffer from a wider range of conditions (see Table 1$)^{[4,5]}$.

Table 1. Classification of life-limiting Conditions according to the Association for Children with Life Threatening or Terminal Conditions and their Families (ACT) ${ }^{[2,3]}$

\begin{tabular}{|l|l|}
\hline Group 1 & $\begin{array}{l}\text { Conditions for which treatment with curative intention is feasible but might fail, e.g., cancer or irreversible organ } \\
\text { failure. }\end{array}$ \\
\hline Group 2 & $\begin{array}{l}\text { Conditions for which there are long periods of intensive treatment aimed at prolonging good-quality life but for } \\
\text { which premature death is anticipated, e.g., cystic fibrosis, muscular dystrophy. }\end{array}$ \\
\hline Group 3 & $\begin{array}{l}\text { Progressive condition where treatment is exclusively palliative from the time of diagnosis and may extend over } \\
\text { many years, e.g., metabolic disorders. }\end{array}$ \\
\hline Group 4 & $\begin{array}{l}\text { Conditions with severe disability, often neurological, which although not progressive cause extreme vulnerability } \\
\text { to health complications and where premature death is anticipated, e.g., severe cerebral palsy, chromosomal } \\
\text { disorders. }\end{array}$ \\
\hline
\end{tabular}

Since April 2007, the individual right to specialist palliative home care is ancored in the German social legislation ${ }^{[6]}$. Children and adolescents suffering from life-limiting diseases are eligible for pediatric palliative home care ${ }^{[7]}$. Specialist care consultant teams are required to meet this demand. They deliver palliative home care on demand, additionally to regional health care services. General care providers play a prominent role in palliative home care ${ }^{[8,9]}$. In Germany, home nursing teams are indispensable in this regard. They collaborate with resident pediatricians and other health care providers.

The provision of palliative home care for adults is a special challenge within rural areas, as service providers have to deal with low population density and long distances ${ }^{[10,11]}$. Due to the lower case numbers, it is even more difficult to provide a comprehensive specialist palliative home care for children and adolescents. A close collaboration of specialist and general care providers can help to meet this challenge. Lower Saxony is a German federal state with nearly eight million residents and predominantly rural areas. So far, only pediatric oncology services provided pediatric palliative home care in this region. These initiatives were not able to assure an area-wide professional service, so that to some extent adult palliative care teams provided services for children or they had to be admitted to hospital. This problem is also known in other countries ${ }^{[12]}$.

Nursing services play a decisive role in pediatric palliative care in the community ${ }^{[13]}$. They are particularly important for symptom control, emotional support and practical help for children and their families ${ }^{[14]}$. Supporting and empowering these services can add to the improvement of palliative home care for children.

The study aimed on the evaluation of involvement in and contribution of home nursing teams to pediatric palliative care as well as their networking with other pediatric palliative care providers. Furthermore, a specialist pediatric palliative home care (SPPHC) should be implemented all over Lower Saxony, adapted on the needs of the regional health care providers and financed by health insurance. 


\section{Subjects and methods}

\section{Evaluation of the initial situation in pediatric palliative care in Lower Saxony}

The current status of pediatric palliative home care by home nursing teams was evaluated using a standardized questionnaire. This instrument was based on an established questionnaire which had been developed in a survey with resident pediatricians in North-Rhine Westphalia (NRW), another German federal state ${ }^{[15,16]}$, and a review of the literature ${ }^{[17-21]}$. It comprises four thematic areas.

- Previous experience with and dispositions to provide pediatric palliative care,

- Interprofessional networking and transition from inpatient to home care

- Perceived barriers and incentives specifically associated with the involvement of nursing services in pediatric palliative care ${ }^{[17,20,21]}$

- Demographical characteristics and details on the home nursing services

Potential difficulties and incentives were evaluated using a homogeneous item-and-response format (six-point Likert scales). Data on patients' characteristics, management, and networking were asked referring to 2008 and 2009.

The questionnaire survey with nursing services was conducted between January and February 2010. Therefore, all 22 home nursing teams caring for children in Lower Saxony were identified by contacting the pediatric home nursing teams cooperating with the Hannover Medical School. Those teams were asked for other home nursing teams caring for children in Lower Saxony. All of the teams identified as relevant by the applied snowball sampling were contacted by mail, 14 of them returned the completed form (Response rate $=63 \%$ ). Ethical approval for the study was given by the Ethics Committee of the Medical School Hannover.

\section{I mplementation of a specialist pediatric palliative home care}

A Pediatric Palliative Working Group was founded to develop a concept on comprehensive SPPHC tailored for a region of low population density ${ }^{[22]}$. The multi-professional Working Group unifies colleagues from regional child clinics, socialpediatric centers, psycho-social services, pediatric home nursing services and pediatric home hospice services.

To facilitate high quality health care, the implementation of SPPHC was framed by quality management for specialist pediatric home nursing services ${ }^{[23]}$. Therefore, the requirements of the German social legislation for specialist pediatric palliative service providers were supplemented by 20 quality criteria of an existing regional initiative, the Quality Association for Pediatric Nursing Home Services in Lower Saxony.

\section{Data on specialized care provision}

The SPPHC team needed a uniform documentation system, with on side availability all over Lower Saxony to ensure real-time prescription and application of medication for symptom control. This system had to meet the requirements of data security ${ }^{[24]}$. Further demands on the documentation system were a billable activity recording and the possibility to evaluate health care delivery and its outcome.

Therefore an online data base was developed for the SPPHC in Lower Saxony considering the guidelines on palliative care database of the German Society of Palliative Medicine (DGP) ${ }^{[25]}$. 


\section{Results}

\section{I nitial situation of pediatric palliative home care in Lower Saxony delivered by nursing teams}

\section{Sample}

Half $(7 ; 50.0 \%)$ of the participating nursing services worked in a mainly rural environment, and 5 (35.7\%) predominantly worked in an urban area. Two (14.2\%) of the nursing teams did not specify their working region. The services' catchment area had a mean radius of 74 kilometers. They existed for 13 years on average (range 6 month - 20 years). Five (35.7\%) of the nursing teams were exclusively pediatric, and 9 (64.3\%) were adult nursing service also caring for children and adolescents. In 2008 the number of patient contacts was 115 per quarter-year on average (164 for adult nursing services, 29 for pediatric nursing services). The average services' personnel comprised 14 full-time and 26 part-time employees (range 4 to 159 employees).

\section{Previous experience with and dispositions to provide pediatric palliative care}

Thirteen of the 14 services (92.9\%) were experienced with palliative care, 9 (64.3\%) had taken care of children in the terminal phase at home. In 2008, nursing services cared for 168 children suffering from LLC (2009 = 181); 21 (12.5\%) of these children died in the same year $(2009=14 ; 7.7 \%)$.

\section{Interdisciplinary and trans-sectional professional networking}

Asked for the existence of local specialist pediatric palliative care providers, $10(71.4 \%)$ of the nursing teams mentioned a local children's hospital, 9 (64.3\%) named pediatric home hospice services, 8 (57.1\%) resident pediatricians, 7 (50.0\%) parents' associations and $5(35.7 \%)$ a children's hospice. The existence of a specialized psychotherapist was reported by 4 (28.6\%) of the home nursing teams.

In 2008, 9 (64.3\%) of the participants collaborated with resident pediatricians for the provision of care as well as with a child's hospital. Six (42.9\%) of the services attested to cooperate with a children's hospice, 4 (28.6\%) with a parent's association and 3 of them with home hospice services as well as with psychotherapists. Three (33.3\%) of the 9 adult home nursing teams cared for children with LLC together with nursing services exclusively pediatric.

More than half of the questioned nursing services (8; 57.1\%) attested problems during the transition from inpatient to outpatient pediatric palliative care. The main problem was poor information flow between the children's hospital, parents and general pediatricians $(7 ; 50.0 \%)$. The main problem in this regard was the preparation of patients and pediatricians for crisis intervention. Another mentioned problem was a lack of specialists (6; 42.8\%).

\section{Perceived barriers and incentives specifically associated with the involvement of nursing services in pediatric palliative care}

The nursing teams were also asked for a rating of barriers and incentives for the implementation of pediatric palliative home care.

Financial burden was mentioned as most relevant barrier by 5 (35.7\%) of the nursing teams, followed by time demand, emotional distress and insecurity with regard to diagnosis, characterized as a relevant barrier by $2(14.3 \%)$ of the services.

Thirteen of the nursing teams (92.9\%) considered education in basic palliative care and the training of communication skills as favourable facilitations for the implementation of pediatric palliative home care. The availability of local 
specialist services as well as a 24/7 on-call telephone service were favored by 12 (85.7\%) of the nursing teams for pediatric palliative care. A sufficient information exchange with other care providers was rated as an important incentive by 10 (71.4\%) of the home nursing services (see Figure 1).

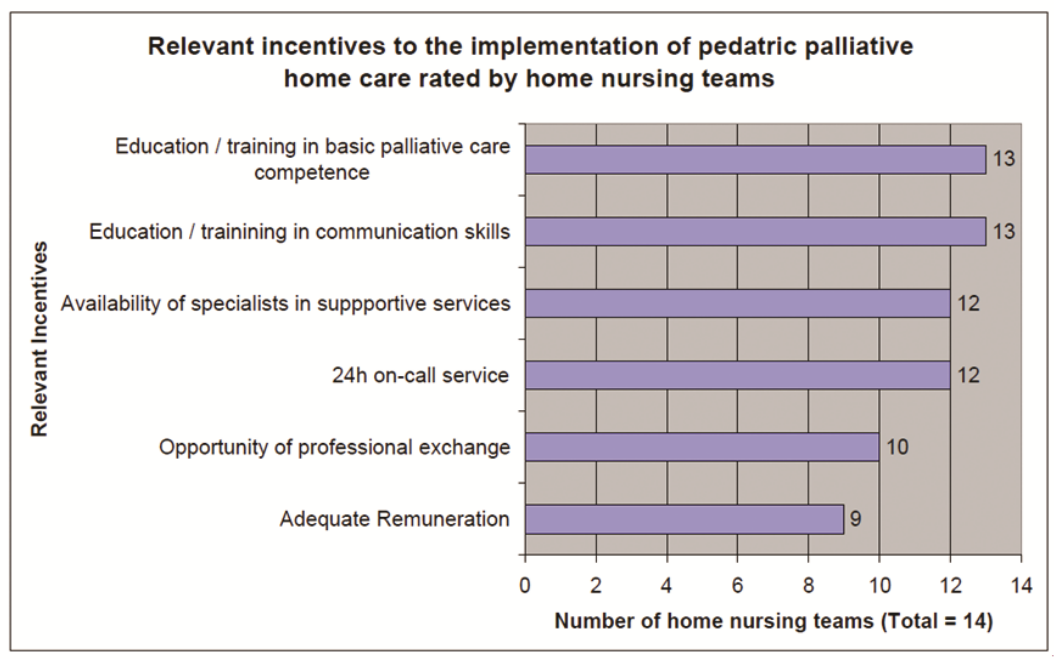

Figure 1. Relevant Incentives to the Implementation of Pediatric Palliative Home Care rated by Nursing Teams

\section{I mplementation of a specialist pediatric palliative home care}

A private limited liability company was funded as responsible body for the SPPHC team in Lower Saxony. A central office and regional teams comprising nursing, medical, and psycho-social specialists were established for delivering SPPHC. The central office mainly undertakes coordination and administration services while the regional teams provide home care for the children and adolescents suffering from complex conditions due to LLC. Both of them work in close cooperation with the regional primary health care team and volunteer services. Additionally a central hotline service provides 24/7 specialist availability. Since April 2010, the newly implemented SPPHC is funded by the statutory health insurance.

\section{Quality management}

Quality management is an integral part of the concept on comprehensive specialist pediatric palliative home care in Lower Saxony ${ }^{[23]}$. Asked for their quality management efforts, 10 of the nursing services participating in the study quoted to take part in a quality circle or a working group, 4 of these being pediatric nursing services. Nine (64.3\%) of the services used a standard for transition from inpatient to outpatient care, again 4 of them being pediatric services. Eleven (78.6\%) home nursing services worked with a quality management system, which was implemented 4 years ago on average.

The 4 pediatric services stating to work with a quality management system maintained a joint structure especially tailored for pediatric home nursing in Lower Saxony. The development of this quality management was supported by the Lower Saxony Ministry of Social Affairs. Core aims of the initiative were the funding of a Quality Association for Nursing Home Services in Lower Saxony and the joint development of twenty quality criteria (see Table 2). These criteria are binding for all member services of the Quality Association and shall ensure a high quality in pediatric home care in Lower Saxony.

Specialist nurses delivering SPPHC have to comply with the requirements of the German Social Security Code V. These are

- advanced training in pediatric palliative care, and

- two years of experience in pediatric palliative care during the last three years.

For nurses delivering SPPHC in Lower Saxony the Pediatric Palliative Working Group added the commitment to work with 
- the 20 quality criteria of the Quality Association for Nursing Home Services.

This integration of existing structures in implementing SPPHC should facilitate a regional tailored high quality specialist pediatric home care.

Table 2. Quality criteria of the Quality Association for Nursing Home Services in Lower Saxony

\begin{tabular}{|l|l|}
\hline \multirow{5}{*}{ Basic Criteria } & 1. Job training of new staff \\
& 2. Planning affecting training \\
& 3. Related care \\
4. Working with care teams & 6. Handling of care documentation \\
& 7. Nurst visit \\
8. Complaint management & 9. (Telephone) accessibility \\
& 10. Written care agreements \\
\hline \multirow{5}{*}{ Special Criteria } & $\begin{array}{l}\text { 1. Qualification of staff \& standards } \\
\text { 2. Transition of care } \\
\text { 3. Guidance \& consultation in nursing home care (German Social Security Code V) } \\
\text { 4. Patient centred internal Case Conferences } \\
\text { 6. Fellow consultation, supervision \& psycho-social training } \\
\text { 7. Family-based care } \\
\text { 8. Intensive pediatric care } \\
\text { 9. Care-relevant cooperation } \\
\text { 10. Terminal care }\end{array}$ \\
\hline
\end{tabular}

\section{Provision of specialist pediatric palliative home care}

During the first 3 years of operation, the SPPHC providers were involved in the management of 131 children suffering from LLC, 74 (56.5\%) of these children died in the same period. In total, 6452 hours of multi-professional SPPHC were delivered, predominantly spent on joint patient care with regional health care providers (30.2\%), driving time (22.5\%) and coordination of care (15.3\%). Divided by profession, psycho-social specialists performed 408 hours (6.3\%) of SPPHC, medical specialists delivered 2331 hours (36.2\%) of care and the central office team performed 792 hours (12.3\%). With 2920 hours of SPPHC, specialist nurses delivered 45.3\% of SPPHC in Lower Saxony (compare Table 3).

Table 3. Hours of Specialist Pediatric Palliative Home Care delivered by Specialist Nurses by Type of Service

\begin{tabular}{lll}
\hline Type of Service & Hours & Percentages \\
\hline Joint patient care (with regional primary health care services) & 1218.42 & $41.73 \%$ \\
Journey time & 914.53 & $31.32 \%$ \\
Coordination & 331.30 & $11.35 \%$ \\
Consultation & 128.92 & $4.42 \%$ \\
Documentation & 106.23 & $3.64 \%$ \\
Case conferences & 90.28 & $3.09 \%$ \\
Full Patient Care & 56.00 & $1.92 \%$ \\
Family follow-up care & 44.58 & $1.53 \%$ \\
Organisation & 14.58 & $0.50 \%$ \\
24h-on-call Service & 13.23 & $0.45 \%$ \\
Medical leadership & 1.33 & $0.05 \%$ \\
Administration & 0.58 & $0.02 \%$ \\
& 2919.98 & $100 \%$ \\
\hline
\end{tabular}




\section{Discussion}

The study aimed on the evaluation of involvement in and contribution of home nursing teams to pediatric palliative care and their networking with other palliative care providers for children and adolescents as well as the implementation of a comprehensive SPPHC in Lower Saxony.

\section{I nitial Situation of pediatric palliative home care in Lower Saxony delivered by nursing teams}

Besides evaluating pediatric palliative home care by home nursing teams we collected also data on the resident pediatricians' involvement in and contribution to pediatric palliative care ${ }^{[26]}$. The extrapolation of patient numbers reported by the pediatricians to the population of Lower Saxony results in a prevalence of about 2500 children suffering from life-limiting diseases. This is consistent with the data from international studies, supposing a prevalence of LLC of $0.1 \%$ to $0.15 \%$ in children and adolescents ${ }^{[27-29]}$.

Within the pediatricians' awareness of the existence of other pediatric palliative service providers, pediatric hospice home services and parents' associations were clearly underrepresented when compared to children's hospitals or home care nursing services ${ }^{[26]}$. Only about one-fifth of the pediatricians mentioned hospice home services and parents' associations, while more than half of the nursing teams quoted to know such services in their catchment area. A good cooperation and information exchange between nursing teams and pediatricians could help to optimize care provision for families in need.

Concerning the transition from inpatient to outpatient pediatric palliative care, the information flow and communication, especially between children's hospital staff and both resident pediatricians and parents, has to be improved, because the quality of pediatric palliative care also depends on trans-sectoral cooperation ${ }^{[30,31]}$. Hospital-based palliative care consultants can be very helpful to support the pediatricians and consolidate relationships between hospital staff and community health care providers ${ }^{[32]}$.

Compared to general pediatricians, significant differences could be found in rating barriers to pediatric palliative home care by nursing teams ${ }^{[26]}$. The latter mentioned the financial burden, time demand, emotional distress and insecurity with regard to diagnosis as the most relevant obstacles, while the physicians, identified time demand, lack of exchange possibilities with colleagues, sole responsibility and the lack of special knowledge as most important barriers. Differences in rating barriers between physicians and nurses were already found for the inpatient setting ${ }^{[17]}$. Nurses spend considerably more time with patients and families than physicians, which accounts for the importance of emotional distress and insecurity with regard to diagnosis. The financial burden as the most important barrier for nursing services can be explained by a lack of full cost recovery in home care according to incomplete reimbursement by the German health insurances. Thus home care teams with a great portion of severely ill children risk substantial financial deficits. In 2008, children with LLC represented less than $2 \%$ of the patients of pediatricians, whereas for the pediatric nursing teams an average of $15 \%$ of patients suffered from such diseases. For the nursing teams specialized in adults, children suffering from LLC on average still made up $4 \%$ of all patients.

Education in basic palliative competence and communication as well as the availability of a specialist pediatric care consultant team was requested most for the implementation of pediatric palliative home care. Internal barriers may result from poor communication skills or a lack of palliative care knowledge and skills ${ }^{[21]}$. In this regard, existing guidelines like those on European nursing education in palliative care devised by the European Association for Palliative Care (EAPC) task force ${ }^{[33]}$ or the educational framework for pediatric palliative care developed in Ireland ${ }^{[34]}$ can provide a basis for education tailored to particular regional needs ${ }^{[35]}$. Thereby, a good understanding of the educational desires of staff is essential to develop appropriate educational interventions ${ }^{[36]}$. 


\section{I mplementation and delivery of a specialist pediatric palliative home care}

The provision of an adequate palliative home care is a special challenge within rural areas ${ }^{[10,11]}$. For children suffering from LLC in Lower Saxony this was met by the integration of pre-existing structures and regional institutions like pediatric clinics, social-pediatric centers, psycho-social services, pediatric home hospice services, and the Quality Association for Nursing Home Services. Therewith, a bundling of competences and optimized information flow, communication and networking can be assured between the inpatient and the outpatient setting as well as between specialists and general service providers.

With regard to the type of services mainly delivered by specialist nursing teams in SPPHC, the use of quality criteria like "care-relevant cooperation”, "working with care teams" (including the systematic assignment of personnel by location and qualification) and "transition of care" (see Table 2) represents a helpful tool to optimize SPPHC. They affect the core tasks of specialist pediatric palliative home nursing services in SPPHC: Joint patient care, journey time and coordination of care (see Table 3).

\section{Scope and limitations of this study}

Despite the small sample size of our study and the very special setting of the German health care system, the presented results can to some extend be transferred to other settings with low patient density where comprehensive clinical-based health care is not available.

\section{Conclusion}

The provision of a comprehensive SPPHC in a region of low population density is possible. A high quality care provision can be achieved by the integration of existing structures, the bundling of competences, and good networking. A great deal of coordinative and logistic efforts is needed to enable the SPPHC in each child and all areas. General nursing services as well as nurses in specialized pediatric palliative care play a crucial role in delivering SPPHC. The cooperation of general and specialist health care providers can ensure a comprehensive high quality care.

The attendance of the SPPHC's implementation by quality management significantly facilitated the negotiations with the statutory health insurance on the foundation of the newly implemented specialist service.

\section{References}

[1] Craig F, Abu-Saad Huijer H, Benini F, Kuttner L, Wood C, Feraris PC, Armstrong-Dailey A, Bellani FF, Friedrichsdorf S, Greffe B, Jasenkova M, Ling J, Mammis G, Manfredini L, Jancovic M, O’Reilly M, Trapanotto M, Zernikow B. IMPaCCT: standards of paediatric palliative care. European Journal of Palliative Care. 2007; 14(3): 109-114.

[2] Bluebond-Langner M, Beecham E, Candy B, Langner R, Jones L. Preferred place of death for children and young people with life-limiting and life-threatening conditions: A systematic review of the literature and recommendations for future inquiry and policy. Palliat.Med. 2013. (7 August 2013 last accessed). http://dx.doi.org/10.1177/0269216313483186

[3] Hechler T, Blankenburg M, Friedrichsdorf SJ, Garske D, Hübner B, Menke A, Wamsler C, Wolfe J, Zernikow B. Parents ' Perspective on Symptoms, Quality of Life, Characteristics of Death and End-of-Life Decisions for Children Dying from Cancer. Klin Pädiatr. 2008; 220: 166-174. PMid:18478489 http://dx.doi.org/10.1055/s-2008-1065347

[4] Association for Children with Life Threatening or Terminal Conditions and their Families and Royal College of Paediatrics and Child Health. A guide to the development of children's palliative care services. Bristol, London: ACT, RCPCH; 1997.

[5] Hynson JL. The child's journey: Transition from health to ill-health. In Oxford Textbook of Palliative Care for children. Goldman A, Hain R, Liben S, ed. New York: Oxford University Press, 2012, 13-22.

http://dx.doi.org/10.1093/med/9780199595105.001.0001 
[6] Federal Joint Committee. Directive on the Prescription of Specialized Outpatient Palliative Care (SAPV Directive) 2007. http://www.g-ba.de/downloads/62-492-437/SAPV-RL_2010-04-15.pdf (29 June 2013 last accessed).

[7] Federal Ministry of Justice. § 37 Social Security Code V on Specialized Palliative Home Care. http://www.gesetze-im-internet.de/sgb_5/_37b.html. (29 June 2013 last accessed).

[8] Brueckner T, Schumacher M, Schneider N. Palliative care for older people - exploring the views of doctors and nurses from different fields in Germany. BMC Palliat Care. 2009 Jun 23; 8: 7. http://www.biomedcentral.com/1472-684X/8/7 (29 June 2013 last accessed).

[9] Gott M, Seymour J, Ingleton C, Gardiner C, Bellamy G. 'That's part of everybody's job': the perspectives of health care staff in England and New Zealand on the meaning and remit of palliative care. Palliat Med. 2012; 26(3): 232-41. PMid:21677020 http://dx.doi.org/10.1177/0269216311408993

[10] Cassel JB, Webb-Wright J, Holmes J, Lyckholm L, Smith TJ. Clinical and financial impact of a palliative care program at a small rural hospital. J Palliat Med. 2010; 13(11): 1339-1343. PMid:21034278 http://dx.doi.org/10.1089/jpm.2010.0155

[11] Masso M, Owen A. Linkage, coordination and integration: evidence from rural palliative care. Aust J Rural Health. 2009; 17(5): 263-267. PMid:19785679 http://dx.doi.org/10.1111/j.1440-1584.2009.01089.x

[12] O’Leary N, Flynn J, MacCallion A, Walsh E, McQuillan R. Pediatric palliative care delivered by an adult palliative care service. Pall Med. 2006; 20(4): 433-437. http://dx.doi.org/10.1191/0269216306pm1147oa

[13] Lenton S, Franck L, Salt A. Children with complex health care needs: supporting the child and family in the community. Child Care Health Dev. 2004; 30(3): 191-192. PMid:15104571 http://dx.doi.org/10.1111/j.1365-2214.2004.00416.x

[14] O Brien I, Duffy A. The developing role of children's nurses in community palliative care. Br J Nurs. 2010; $19(15)$ : 977-981. PMid:20966865

[15] Jünger S, Pastrana T, Pestinger M, Kern M, Zernikow B, Radbruch L. Barriers and needs in paediatric palliative home care in Germany: a qualitative interview study with professional experts. BMC Palliat Care. 2010 Jun 2; 9: 10. http://www.biomedcentral.com/1472-684X/9/10 (29 June 2013 last accessed).

[16] Jünger S, Vedder AE, Milde S, Fischbach T, Zernikow B, Radbruch L. Paediatric palliative home care by general paediatricians: a multimethod study on perceived barriers and incentives. BMC Palliat Care. 2010 Jun 4; 9: 11.

http://www.biomedcentral.com/1472-684X/9/11 (29 June 2013 last accessed).

[17] Davies B, Sehring SA, Partridge JC, Cooper BA, Hughes A, Philp JC, Amidi-Nouri A, Kramer RF. Barriers to palliative care for children: perceptions of pediatric health care providers. Pediatrics. 2008; 121(2): 282-288. PMid:18245419 http://dx.doi.org/10.1542/peds.2006-3153

[18] Feeg VD, Elebiary H. Exploratory study on end-of-life issues: barriers to palliative care and advance directives. Am J Hosp Palliat Care. 2005; 22(2): 119-124. http://dx.doi.org/10.1177/104990910502200207

[19] Contro NA, Larson J, Scofield S, Sourkes B, Cohen HJ. Hospital staff and family perspectives regarding quality of pediatric palliative care. Pediatrics. 2004; 114(5): 1248-1252. PMid:15520103 http://dx.doi.org/10.1542/peds.2003-0857-L

[20] De Graves S, Aranda S. When a child cannot be cured - reflections of health professionals. Eur J Cancer Care (Engl). 2005; 14(2): 132-140. PMid:15842460 http://dx.doi.org/10.1111/j.1365-2354.2005.00520.x

[21] Morgan D. Caring for dying children: assessing the needs of the pediatric palliative care nurse. Pediatr Nurs. 2009; 35(2): 86-90. PMid:19472671

[22] Kremeike K, Sander A, Eulitz N, Reinhardt D. Specialized ambulatory pediatric palliative care (SAPPV) - a concept for implementing comprehensive care in Lower Saxony. Kinderkrankenschwester. 2010; 29(10): 419-423.

[23] Kremeike K, Eulitz N, Sens B, Geraedts M, Reinhardt D. Quality management in implementing specialist pediatric palliative home care in Lower Saxony, Germany] Z Evid Fortbild Qual Gesundh wesen (ZEFQ). 2012; 106(8): 584-94.

[24] Bundesministerium der Justiz, juris GmbH - www.juris.de. Bundesdatenschutzgesetz (BDSG). Ausfertigungsdatum 20.12.1990. http://www.gesetze-im-internet.de/bundesrecht/bdsg_1990/gesamt.pdf. (29 June 2013 last accessed).

[25] German Association for Palliative Medicine, German Hospice and Palliative Assocation. Common database. http://www.dgpalliativmedizin.de/category/6-nationales-hospiz-und-palliativregister.html?down load=32. (29 June 2013 last accessed).

[26] Kremeike K, Eulitz NK, Jünger S, Sander A, Geraedts M, Reinhardt D. Paediatric palliative home care in areas of Germany with low population density and long distances: a questionnaire survey with general paediatricians. BMC Res Notes. 2012 ; 5(1): 498. http://www.biomedcentral.com/1756-0500/5/498. (29 June 2013 last accessed).

[27] Lenton S, Stallard P, Lewis M, Mastroyannopoulou K. Prevalence and morbidity associated with non-malignant, life-threatening conditions in childhood. Child Care Health Dev. 2001; 27(5): 389-398. PMid:11531912 http://dx.doi.org/10.1046/j.1365-2214.2001.00216.x 
[28] The Irish Hospice Foundation. A Palliative Care Needs Assessment for Children. 2005.

http://hospicefoundation.ie/wp-content/uploads/2012/04/Palliative-care-needs-assessment-for-children-2005.pdf. (29 June 2013 last accessed).

[29] Feudtner C, Hays RM, Haynes G, Geyer JR, Neff JM, Koepsell TD. Deaths attributed to pediatric complex chronic conditions: national trends and implications for supportive care services. Pediatrics. 2001; 107(6): E99. PMid:11389297 http://dx.doi.org/10.1542/peds.107.6.e99

[30] Monterosso L, Kristjanson LJ, Phillips MB. The supportive and palliative care needs of Australian families of children who die from cancer. Palliat Med. 2009; 23(6): 526-536. PMid:19351793 http://dx.doi.org/10.1177/0269216309104060

[31] Carroll JM, Santucci G, Kang TI, Feudtner C. Partners in pediatric palliative care: a program to enhance collaboration between hospital and community palliative care services. Am J Hosp Palliat Care. 2007; 24(3): 191-195. PMid:17601842 http://dx.doi.org/10.1177/1049909106298393

[32] Sheetz MJ, Bowman MA. Pediatric palliative care: an assessment of physicians' confidence in skills, desire for training, and willingness to refer for end-of-life care. Am J Hosp Palliat Care. 2008; 25(2): 100-105. PMid:18445861 http://dx.doi.org/10.1177/1049909107312592

[33] De Vlieger M, Gorchs N, Larkin PJ, Porchet F. A Guide for the Development of Palliative Nurse Education In Europe. 2004; http://www.eapcnet.eu/LinkClick.aspx?fileticket=e9JnEa7YZDM\%3d. (29 June 2013 last accessed).

[34] Phelan J, Godfrey M, O’Leary E. Caring for a Child with a Life-limiting Condition - An Educational Framework to Support Excellence in Practice. Dublin: Health Service Executive; 2006.

[35] Kelley ML, Habjan S, Aegard J. Building capacity to provide palliative care in rural and remote communities: does education make a difference? J Palliat Care. 2004; 20(4): 308-315. PMid:15690834

[36] Gallagher K, Cass H, Black R, Norridge M. A training needs analysis of neonatal and paediatric health-care staff in a tertiary children's hospital. Int J Palliat Nurs. 2012; 18(4): 197-201. PMid:22584391 